\title{
Compartilhamento de conhecimentos em uma feira livre: reflexões sobre os relacionamentos entre feirantes e fregueses
}

As feiras livres são espaços destinados tanto ao comércio quanto ao lazer e encontros, tornando-se ambientes propícios ao compartilhamento de conhecimentos. Apesar da sua riqueza para estudos organizacionais, não têm havido pesquisas que tratem do compartilhamento de conhecimento em tais contextos. Neste sentido, o objetivo da pesquisa foi investigar como os feirantes compartilham conhecimentos entre si e com os fregueses, destacando a natureza dos relacionamentos entre os mesmos. Para tanto, realizou-se uma pesquisa qualitativa, através de entrevistas semiestruturadas, com feirantes e fregueses da Feira Livre de Campina Grande-PB. Os resultados apresentaram alguns exemplos de compartilhamento de conhecimentos, além de indicar que os relacionamentos são permeados por amizade, lealdade e confiança entre feirantes e fregueses. Já, entre os próprios feirantes, verificou-se distanciamento, polidez e deslealdade.

Palavras-chave: Compartilhamento de Conhecimento; Feirantes e Fregueses; Feira Livre de Campina Grande.

\section{Sharing of knowledge in a fair: reflections on the relationships between marketers and customers}

\begin{abstract}
The fairs are spaces for both the business as leisure and meetings, becoming environments conducive to knowledge sharing. Despite its wealth to organizational studies, there have been no studies that deal with the sharing of knowledge in such contexts. In this sense, the present investigates how the vendors share knowledge with each other and with customers, emphasizing the nature of relationships between them. For this purpose, a qualitative research was conducted through semi-structured interviews with marketers and costumers of the Free Fair of Campina Grande-PB. The results show some knowledge sharing examples, besides indicating that relationships are permeated with friendship, loyalty and trust between merchants and customers. Already, between the vendors themselves, there was detachment, politeness and disloyalty.
\end{abstract}

Keywords: Knowledge Sharing; Marketers and Customers; Free Markets of Campina Grande.

Topic: Terceiro Setor e Cooperativismo

Reviewed anonymously in the process of blind peer.

Francilene Araújo de Morais

Universidade Presbiteriana Mackenzie, Brasil

http://lattes.cnpq.br/1546276244212200

francilene.morais7@gmail.com

Fábio de Oliveira Lucena

Universidade Presbiteriana Mackenzie, Brasil

http://lattes.cnpq.br/2014110572667710

flucena1968@gmail.com

Silvio Popadiuk

Universidade Presbiteriana Mackenzie, Brasil

http://lattes.cnpq.br/1784002683973468

spopadiuk@gmail.com
Received: 10/06/2016

Approved: 23/11/2016
Referencing this:

MORAIS, F. A.; LUCENA, F. O.; POPADIUK, S.. Compartilhamento de conhecimentos em uma feira livre: reflexões sobre os relacionamentos entre feirantes e fregueses. Revista Brasileira de Administração Científica, v.7, n.3, p.267-282, 2016. DOI: http://doi.org/10.6008/SPC2179-684X.2016.002.0019 


\section{INTRODUÇÃO}

As feiras livres são espaços abertos destinados tanto ao comércio quanto ao lazer e encontros, na medida em que as pessoas se reúnem para vender, comprar e trocar produtos ou, simplesmente, para conversarem e trocarem ideias, em dias e horários preestabelecidos. Perduram desde a antiguidade e desempenham um papel relevante na construção das cidades e respectivas consolidações econômicas, históricas, social e cultural (SÁ, 2010).

Nos tempos modernos, as feiras têm diversificado ao máximo seu tipo de comércio, oferecendo desde produtos sofisticados até coisas simples de que a classe C e D precisam. Hoje as feiras livres se confundem com os mercados formais, diferentemente da Idade Média, e passam a ser um comércio que centraliza compradores e vendedores (MAIOR, 1978).

Assim como diversas outras cidades do mundo, a Feira Livre de Campina Grande, na Paraíba, é um espaço peculiar de comércio, que ultrapassa as transações comerciais propriamente ditas, passando a ser uma atividade profissional marcada pelas relações estabelecidas entre vendedores e fregueses e entre os próprios feirantes, constituindo-se assim, num espaço propício ao compartilhamento e criação de conhecimentos (CARDOSO et al., 2010).

Compartilhamento de conhecimento diz respeito ao conhecimento que é transmitido do emissor para o receptor, ficando o conhecimento tanto com o emissor quanto com o receptor (FAYE et al., 2008). Já a criação do conhecimento deriva diretamente da interação entre pessoas (NONAKA et al., 1995).

A revisão da literatura pertinente possibilitou identificar que o tema feira livre, apesar de amplo enquanto possibilidade de estudo, é pouco explorado no âmbito organizacional. Notou-se que as principais temáticas estudadas correspondem aos seguintes assuntos: feira de negócios e estratégias de marketing; identidade e construção de estratégia em organização informal; feira, enquanto negócio; fatores que afetam o desempenho dos expositores; credibilidade dos produtos vendidos; metodologia usada em estudos envolvendo feira; identificação dos feirantes e seus negócios. A ausência de pesquisas sobre compartilhamento de conhecimento e relacionamentos que favorecem tal troca em feira livre se constituiu uma lacuna do conhecimento, o que motivou o presente estudo.

Tendo em vista o peculiar ambiente da feira livre, que é marcado por relações informais, realizou-se uma pesquisa, de caráter qualitativo, com feirantes, donos de barracas de diversos produtos, na Feira Livre de Campina Grande, com o objetivo de identificar como os mesmos compartilham conhecimentos entre si e com os fregueses, destacando os tipos de relacionamentos entre os mesmos.

Acredita-se tratar de relevante investigação científica, tanto do ponto de vista teórico quanto empírico, uma vez que, fortalece os estudos sobre compartilhamento de conhecimentos em ambientes organizacionais diferenciados, como é o caso, da feira livre. Nota-se que existe uma tendência atual dos grandes centros ou grandes empresas implantar em seu cotidiano organizacional práticas gerenciais que levem em consideração singularidades e especificidades das pequenas ou informais organizações, buscando 
assim, compreender as reais necessidades dos clientes, buscando atendê-las e, por fim, torná-los mais satisfeitos (SAMARA et al., 2005; KARSAKLIAN, 2004).

Este artigo está dividido em cinco seções. A introdução apresenta os objetivos da pesquisa, seus principais pilares teórico-metodológicos e alguns aspectos sobre a feira livre. A segunda seção traz um breve levantamento da literatura sobre a feira livre, destacando a feira de Campina Grande, bem como aspectos teóricos relacionados ao compartilhamento de conhecimentos e o " $\mathrm{Ba}^{1}$. A terceira seção, por sua vez, aborda os procedimentos metodológicos utilizados nesta pesquisa. A quarta seção trata dos resultados e análises dos dados. Na quinta seção são apresentadas as considerações finais. Uma última e sexta seção apresenta as referências das fontes bibliográficas empregadas no artigo.

\section{REVISÃO TEÓRICA}

\section{As feiras livres}

A etimologia da palavra feira aponta que a palavra latina "feria" se refere a dia santo ou feriado, demonstrando a inter-relação existente entre o comércio e a religião. Feria é a palavra latina que deu origem à palavra portuguesa feira, à espanhola feria e à inglesa fair (GIZ DIGITAL, 2016).

Desde a antiguidade, as feiras livres constituem um importante meio de comercialização e também um espaço de lazer e de encontros, na medida em que as pessoas se reúnem em um determinado local para realizar vendas ou trocas de produtos. Trata-se de um negócio que, ao longo de sua história, vem se transformando e que, apesar de terem, ao longo do tempo, seus espaços reduzidos em função da expansão de outros canais de comercialização, como os supermercados e os shoppings, até hoje, desempenham um papel relevante na consolidação econômica, histórica, social e cultural das cidades (GOMES et al., 2013; SALES et al., 2011).

Além disso, conforme assinalam Ferreira et al. (2011), apesar da concorrência imposta pelos empreendimentos de grande porte, que se instalaram nos centros urbanos, as feiras livres continuam na modernidade sendo espaços abertos e democráticos, característico da cultura nordestina.

Em relação as suas peculiaridades e singularidades, Sales et al. (2011) destacam que a feira livre é um ambiente singular de comércio em função de várias características, tais como: a) oferta de produtos diferenciados e de qualidade; b) relações de amizade e confiança estabelecidas entre vendedores e fregueses, que favorecem os feirantes conhecerem as necessidades e desejos dos seus clientes e, dessa forma, aprimorar aspectos produtivos e de venda, a fim de atender continuamente a essas necessidades; c) ambiente intrinsecamente lúdico, que ultrapassa o espaço de comercialização e se constitui em um ambiente de encontros, conversas, articulações e diversões.

A feira livre, segundo Ferreira et al. (2011) e Cavedon (2002), é um ambiente democrático e movimentado, cheio de sons, cores, cheiros, odores etc. Os aromas se misturam: o perfume exalado pelas frutas e flores se funde com os odores dos peixes. Pessoas de posses e pobres, brancos e negros, turistas ou

\footnotetext{
${ }^{1}$ Lugar ou espaço onde as pessoas interagem entre si (NONAKA et al., 1998).
} 
não, letrados ou não, todos circulam pelas feiras. Já para Sá (2010), é um ambiente onde se mesclam o tradicional e o moderno e, nas palavras de Cavedon (2002), nela o profano e o sagrado se mesclam. Trata-se de um ambiente paradoxal, de um espaço democrático, alvo de vários estudos e interpretações.

Apesar de se tratar de um espaço lúdico, de amizades e de oportunidades para os clientes adquirirem produtos "novos", de boa qualidade e de procedência segura, Sales et al. (2011) chamam a atenção para o fato de que a feira é um negócio e que precisa fazer uso de práticas administrativas, a fim de garantir a sobrevivência dos feirantes, como empreendedores, no mercado competitivo em que estão inseridos. Inclusive, ressaltam que, na medida em que a feira livre é entendida como um negócio, este canal de comercialização se torna um forte instrumento de políticas públicas e um grande gerador de emprego e renda para o município.

Sá (2010) considera que a feira livre, apesar de perdurar desde a antiguidade e ser uma atividade econômica e social relevante à vida de muitos brasileiros, em especial aos nordestinos, hoje está ligada à dinâmica do capitalismo contemporâneo, sendo constituída pelas instituições chaves da modernidade, Estado e mercado. Diferentemente de Sales et al. (2011), que enxergam a feira como um negócio gerador de empregos, Sá (op.cit.) afirma que a feira não se mostra capaz de gerar empregos para parte significativa da população e, ao mesmo tempo, desenvolve-se de modo relativamente distinto, conforme a condição geopolítica da região. No interior do Nordeste, por exemplo, a feira é um espaço onde os trabalhadores nordestinos lutam por subsistência ou pelo sonho de uma vida melhor (SÁ, 2010).

\section{A Feira Livre de Campina Grande}

Assim como em diversas outras cidades do Nordeste, a origem da Feira de Campina Grande, na Paraíba, relaciona-se diretamente à própria origem da cidade, bem como ao processo de urbanização do Brasil. Localizada aos arredores de um caminho colonial próximo à estrada real, Campina Grande, segundo Cardoso et al. (2010), desde sua origem, é o tipo da cidade mercado, que se relaciona tanto com outras regiões da Paraíba, como por exemplo, o sertão, o brejo e a capital, quanto com outros Estados do Nordeste, a saber: Pernambuco e Rio Grande do Norte.

Por se tratar de uma rota estratégica, segundo Ferreira et al. (2011), essa região aglomerava tropeiros e boiadeiros, facilitando, assim, o comércio e trocas de diversos produtos, tais como, farinha de mandioca, algodão, carne, cordas, milho, frutas, cana, aguardente etc. Ademais, conforme Cardoso et al. (2010), a Feira de Campina Grande se destacou pelo papel centralizador em virtude da própria condição geográfica, onde está localizada.

Ao comparar o papel centralizador da Feira de Campina Grande de outrora com a feira dos dias atuais, Cardoso et al. (2010) afirmam que esta feira já não possui a mesma imponência. Alegam que há um elevado número de feiras que passaram a ocorrer nas outras cidades da Paraíba e do Nordeste como um todo, inclusive nos mesmos dias preestabelecidos para a Feira de Campina Grande (principalmente quinta, sexta e sábado), diminuindo, assim, a necessidade das pessoas dos outros interiores e Estados se deslocarem para Campina Grande, com o objetivo de comprar e vender os seus produtos. 
Mesmo assim, a Feira de Capina Grande continua sendo um espaço integrador, que liga o campo à cidade, pois é para as feiras que se dirigem os agricultores e criadores. O dia da feira é marcado por muita movimentação, conversas, compras e vendas de produtos diversificados. É o momento dos pequenos agricultores da redondeza trazerem os seus produtos para serem vendidos e se abastecerem de outros gêneros. É também o momento do encontro com o esperado e amigo cliente, além de um espaço destinado às amizades e diversas conversas, que variam desde problemas familiares, religião, política, até dicas de receitas e remédios. Na feira, encontra-se uma diversidade ampla de produtos, desde gêneros alimentícios, incluindo carnes, legumes, frutas, verduras, queijo, coco e doces. Até roupas, calçados, flores, utensílios domésticos, plásticos, louças, chapéus, chicotes, botas, CDs, DVDs, entre outros produtos.

Especificamente em relação à Feira de Campina Grande, que tanto impulsionou o crescimento e desenvolvimento da cidade, os autores chamam a atenção para as características paradoxais desta feira, marcada pela mistura do novo com o velho, do rural com o urbano, do moderno com o tradicional (CARDOSO et al., 2010). Exemplificando, eles dizem que na Feira Livre de Campina se encontram desde produtos manufaturados de maneira rudimentar, como lamparinas feitas de restos de latas; abano de palha para fogão; chapéus de couro e de palha, até aparelhos eletrônicos e serviços, como "disque feira" e "disque frete". Comentam, ainda, que as feiras desempenham relevante papel na socialização dos indivíduos, uma vez que proporcionam condições para encontros e reencontros, marcados por suas especificidades e singularidades, em dias e horários preestabelecidos, conforme observado anteriormente.

\section{Compartilhamento de Conhecimento}

Antes de analisar as características do compartilhamento de conhecimento e a maneira como este ocorre, faz-se necessário esclarecer que este assunto é abordado na literatura com abordagens diferentes, contudo convergem para a mesma questão. Por exemplo, três termos são usados para descrever este assunto: transferência de conhecimento, troca e partilha de conhecimentos e compartilhamento de conhecimento. Embora cada um destes termos se relacione com diferentes perspectivas, objetivos e interesses e não existir uma superioridade de uns sobre os outros, esta diversidade de conceitos dificulta as pesquisas na área, no que se refere à imprecisão do termo. Sendo assim, compartilhamento de conhecimento diz respeito ao conhecimento que é transmitido do emissor para o receptor, ficando o conhecimento tanto com o emissor quanto com o receptor (FAYE et al., 2008).

Faye et al. (2008) relatam transferência de conhecimento sob a perspectiva de disseminação do conhecimento, que por sua vez, constitui a base das seguintes abordagens: linear, bidirecional, interativa. $\mathrm{Na}$ abordagem linear, os pesquisadores e especialistas geram conhecimentos e os repassam para os usuários, de maneira unidirecional, sem levar em consideração as preocupações e expectativas dos usuários. Contrariamente a esta abordagem, no modelo bidirecional, identificam-se as necessidades e preocupações dos futuros usuários, construindo assim, um intercâmbio entre emissores e usuários. Já na perspectiva interativa, como o próprio nome sugere, existe uma troca entre emissores e receptores e a transferência de conhecimento ocorre mediante esta interação (FAYE et al., 2008). 
A transferência de conhecimento ocorre de maneira formal e informal, podendo envolver: resultados de pesquisas; tecnologia; aprendizagem; e organizacional (FAYE et al., 2008). Já, em relação à utilidade da transferência, os autores apontam três: instrumental, conceitual, simbólica ou estratégica. A primeira consiste em modificar uma ação ou subsidiar uma decisão. A segunda é mais informativa do que prescritiva. Conduz a tomada de decisão e também a ações de curto prazo, uma vez que o conhecimento traz novas ideias que influenciam a compreensão. Por fim, a utilidade simbólica ou estratégica da transferência se refere ao fato de que o conhecimento é usado como um argumento de autoridade para legitimar ou justificar posições ou decisões.

Quando há diversos componentes tácitos na transferência do conhecimento, Szulanski (1996) coloca que um relacionamento árduo, que é trabalhoso e distante, pode criar dificuldades adicionais na conversão do conhecimento. $\mathrm{O}$ autor acrescenta que é preciso ver a transferência como um processo, com vistas a melhor compreender as dificuldades inerentes à conversão do conhecimento.

Dependendo das abordagens e definições adotadas, existem diferentes processos ou modelos de transferência do conhecimento. Os principais modelos descritos por Faye et al. (2008) são: fluxo linear, colaborativo, interação, intercâmbio e partilha de conhecimento, conforme descritos a seguir.

No modelo de fluxo linear, que é eminentemente unidirecional, a transferência de conhecimento entre transmissores e receptores é representado por fluxos em que os emissores assumem um papel ativo e os receptores se apresentam mais passivos. A influência do contexto e características individuais (nível, experiência, etc.) sobre o processo ou sobre a finalidade da transferência estão ausentes (FAYE et al., 2008).

No modelo colaborativo, evidenciase trocas regulares entre produtores e usuários do conhecimento. As trocas estabelecidas entre ambos são destinadas a integrar as preocupações dos usuários, podendo acontecer em várias de suas fases. Também são usadas para mostrar as relações que existem entre os dois centros de criação do conhecimento: pesquisa e ação. Estas relações são caracterizadas por um fluxo alternativo, contínuo e progressivo, que pode assumir a forma de uma espiral (FAYE et al., 2008).

No modelo de interação, a troca entre emissores e receptores é mais elaborada e ocorre de maneira circular. Este modelo envolve, por um lado, a existência de relações de colaboração entre um conjunto de atores, e, por outro lado, uma reflexão sobre o contexto em que os usuários operaram e como a transferência de conhecimento ocorre. Nesse modelo, o conhecimento é o resultado de interações entre atores de diferentes sistemas (FAYE et al., 2008).

Em modelos de intercâmbio e partilha de conhecimento, o processo de interação entre os diversos grupos sociais, tais como pesquisadores, tomadores de decisão e usuários, é central e resulta em redes de intercâmbio. Pesquisadores produzem um conhecimento que pode ser melhorado por meio de feedback dos usuários através de canais de intercâmbio. O central para estes modelos é o produto final, ou seja, a utilização dos resultados, a avaliação do grau como os objetivos foram atingidos, e a influência e impacto dos resultados por meio de sua aplicação e utilização (FAYE et al., 2008).

Nota-se, através destes quatro modelos de transferência de conhecimento relatados por Faye et al. (2008) que, cada vez mais, os usuários estão tendo um papel ativo na construção do conhecimento. Em 
relação aos fatores que facilitam a transferência de conhecimentos, Faye et al. (2008) informam que estes irão variar, de acordo com os objetivos pretendidos, a estratégia escolhida e o contexto organizacional. Entre estes fatores, destacam-se: fornecimento, em tempo hábil, de soluções sobre questões de interesse dos usuários; definição de uma estratégia clara de divulgação dos resultados desde o início; combinação de vários métodos para divulgação dos resultados, etc.

Segundo Gubbins et al. (2012), para transferir o conhecimento tácito, é preciso externalização e internalização. A dificuldade é intensificada porque o repositório fundamental do conhecimento tácito está nos indivíduos (ARGOTE; INGRAM, 2000), sendo necessária habilidade e boa vontade das pessoas para externalizar o mesmo de modo que as outras pessoas possam entendê-lo.

Já, em relação aos impactos do conhecimento transferido na organização, estes podem ter provocado efeitos esperados, inesperados, positivos, negativos. Isto vai depender do tipo de atividade e área organizacional, em que a transferência de conhecimento ocorreu. Entre os possíveis efeitos da transferência do conhecimento, Faye et al. (2008) apontam: a) valorização do conhecimento transferido para produtos inovadores e rentáveis, processos, serviços ou tecnologias; b) progressos e avanços; c) decisões tomadas com base no conhecimento transferido; d) problemas resolvidos no todo ou em parte, com base no conhecimento transferido; e) contribuição do conhecimento transferido para o capital humano e para o capital técnico.

No compartilhamento de conhecimento, podem ocorrer algumas dificuldades ou obstáculos, tais como: linguagem, emoções, crenças, valores, etc. A dificuldade da linguagem aparece em contextos em que os indivíduos, apesar de terem conhecimentos, esbarram na dificuldade de compartilhá-los em função da falta de domínio do idioma. Esta dificuldade também aparece entre pessoas que compartilham o mesmo idioma e ocorre devido à falta de habilidade de expressão oral (MORANDIM, 2003).

As emoções, crenças e valores, por sua vez, também interferem no compartilhamento de conhecimentos, tanto maximizando a relevância do conhecimento que precisa ser compartilhado quanto minimizando. $O$ interesse, a necessidade de saber um tipo particular de assunto são aspectos, que aliados à percepção, memória, atenção, esforço, persistência, concentração, etc. interferem no compartilhamento de conhecimentos e, por conseguinte, na criação ou modificação de conhecimentos (NOVAES, 1980; BOCK et al., 2008).

Morandim (2003) enfatiza que as emoções, os sentimentos e os modelos mentais dos indivíduos precisam ser compartilhados a fim de favorecer o desenvolvimento da confiança mútua. $\mathrm{O}$ autor acrescenta que a confiança mútua é necessária à transferência de conhecimento, principalmente à do conhecimento tácito, assim como o estabelecimento de um ambiente onde os indivíduos interagem de forma cooperativa uns com os outros.

\section{Conhecimento e "Ba"}

O conceito de conhecimento é amplo e pode ter diferentes significados, consoante o referencial filosófico-teórico adotado pelo autor. O conhecimento, por exemplo, pode ser classificado em dois tipos: tácito e explícito. O primeiro se refere ao conhecimento que é mais fácil de ser demonstrado do que 
codificado. Já, o segundo corresponde ao conhecimento que é codificável e transmissível em linguagem formal (NONAKA et al., 2008). O compartilhamento de conhecimento envolve a transferência do conhecimento tácito e explícito entre os indivíduos dentro da organização (NONAKA, 1994).

O conhecimento, para Nonaka e Takeuchi (1995) é criado e expandido através da interação social entre o conhecimento tácito e o conhecimento explícito, o que eles chamam de conversão do conhecimento. Esta pode ocorrer através de quatro modos, a partir da combinação entre o conhecimento tácito e o explícito, quais sejam: a) socialização: conversão do conhecimento tácito em conhecimento tácito; b) externalização: conversão do conhecimento tácito em conhecimento explícito; c) combinação: conversão do conhecimento explícito em conhecimento explícito; d) internalização: conversão do conhecimento explícito em conhecimento tácito.

Nonaka et al. (1995) atribuem caráter dinâmico e contínuo à criação do conhecimento organizacional, que surge a partir da interação entre conhecimento tácito e explícito. Colocam também que o conteúdo do conhecimento criado por cada modo de conversão é diferente. Ou seja, a socialização gera conhecimento compartilhado; a externalização gera conhecimento conceitual; a internalização gera o conhecimento operacional e a combinação gera o conhecimento sistêmico.

Os conteúdos de conhecimentos, gerados através dos quatro modelos de conversão, interagem entre si, construindo novos conhecimentos a partir de diversificadas interações, o que Nonaka e Takeuchi (1995) denominam de espiral de criação do conhecimento organizacional.

Para Nonaka, Toyama e Bonno (2000), a criação do conhecimento requer uma atmosfera propícia, o que eles denominam de "Ba". Trata-se de um termo japonês, que se refere ao lugar ou espaço onde os indivíduos interagem. Neste ambiente ocorre a troca de ideias, e o compartilhamento de conhecimentos, além da construção de uma linguagem comum que sincronize os ritmos mentais e emocionais das pessoas, gerando conhecimentos.

Bennett (2001) e Nonaka et al. (1998) consideram quatro tipos de "Ba". O primeiro tipo, originando Ba, envolve o compartilhamento de sentimentos, emoções, experiências e modelos mentais. Trata-se de um "Ba" necessário na fase de socialização e ocorre face a face. O segundo tipo, interagindo no "Ba", associa-se à externalização do conhecimento e emerge a partir de cenários construídos. O conhecimento tácito se torna explícito através do diálogo, reflexão e compartilhamento de modelos mentais. O terceiro tipo, que é o "Ba" virtual, diz respeito ao uso da comunicação virtual na construção do "Ba", oferecendo um contexto para transmissão de conhecimento explícito para um maior número da população, através de equipamentos eletrônicos e outras mídias, como por exemplo grupos virtuais. O quarto e último tipo, exercitando o "Ba", refere-se à prática do "Ba", que leva a internalização do conhecimento. Isto pode ocorrer através de monitoramento, treinamento e estágio.

Além disso, o "Ba" é um ambiente propício à aprendizagem, que por sua vez, depende de vários fatores, tais como: tentativa e erro, observação e, escuta de histórias sobre como outras pessoas trataram problemas. Tipicamente ocorre mais no nível individual do que organizacional. No processo de criação do conhecimento, evidencia-se a presença de inputs, outputs e moderadores (NONAKA et al., 1998). 
Por fim, observar, conversar, trocar experiências são maneiras pelas quais as pessoas descobrem o que sabem, compartilham conhecimentos e criam conhecimentos, que podem ter utilidade tanto para o indivíduo quanto para a organização. Importante destacar que, neste compartilhamento, podem ocorrer conflitos de ideias e, justamente, através dos diálogos estabelecidos podem levar os emissores e receptores a redimensionarem seus conhecimentos e criarem novos conhecimentos (NONAKA et al., 1995).

Em relação à estrutura do conhecimento, Collins (1993) apresenta quatro elementos, que são: simbólico: refere-se ao conhecimento que pode ser transferido sem perdas, por meios de sinais, como por exemplo o conhecimento que é transferido entre computadores e demais mídias; corporificado: é o conhecimento que depende do corpo, está relacionado com a parte física do cérebro e não com sua atuação cerebral, propriamente dita; mentalizado realça o aspecto cerebral, no qual a geração de conhecimento ocorre através da seleção de objetos e ideias; introjetado pelas culturas; refere-se ao conhecimento sociocultural e depende do ambiente externo e da interpretação.

Levando em consideração que o conhecimento pode ser transferido e decorre da ação humana, Collins (1993) argumenta que apenas uma parte deste conhecimento pode ser transferida. A parte do conhecimento não suscetível de codificação ou mecanização fica na mente humana, aguardando o momento oportuno de ser utilizado. Em outras palavras, o indivíduo sabe, tem conhecimento, mas só se dá conta desta apropriação do saber quando surge uma necessidade e este conhecimento é externalizado (COLLINS, 1993).

Conhecimento e habilidade são diferentes, segundo Collins (1993), e esta diferença ocorre em função de dois tipos de ação humana, que são: conhecimento tácito e conhecimento formal. O conhecimento tácito é o conhecimento que está localizado na sociedade. Já, o conhecimento formal é o conhecimento que pode ser transferido para símbolos e codificado em máquinas e outros artefatos.

Novos conhecimentos surgem, não quando o conhecimento tácito se torna explícito, mas quando o nosso desempenho qualificado - nossa práxis - é pontuada em novas formas através da interação social (TSOUKAS, 2007). O conhecimento tácito, composto por um conjunto de elementos de que somos subsidiariamente conscientes, é um tipo de conhecimento-ainda-não-articulado, ou seja, um conhecimento que existe apenas em uso e não pode ser ainda formulado em regras. O conhecimento tácito não pode ser "capturado", "traduzido" ou "convertido". Apenas exibido ou manifestado no que fazemos (TSOUKAS, 2007).

Tsoukas (2007) acrescenta que o conhecimento tácito e o explícito não são os dois extremos de um continuum, mas os dois lados da mesma moeda: mesmo o tipo mais explícito de conhecimento é sustentado por tácito conhecimento.

\section{METODOLOGIA}

Para alcance dos objetivos preestabelecidos, realizou-se uma pesquisa descritiva, que busca elucidar as características de determinados fenômenos, numa perspectiva individual, organizacional ou orientada para um segmento específico, de modo que se possa identificar algumas práticas organizacionais comuns (SEKARAN, 2003). No presente caso, o segmento foi a feira livre, tendo como unidade de análise os 
relacionamentos entre os próprios feirantes e entre estes e seus fregueses, especialmente no que se refere ao compartilhamento de conhecimentos. O tratamento adotado foi do tipo qualitativo (CRESWELL, 2010).

Como instrumento de pesquisa, usou-se um roteiro de entrevista com perguntas abertas (Apêndice A), na Feira Central de Campina Grande, na Paraíba. Foram entrevistados 35 participantes, sendo 25 feirantes e dez clientes. Os feirantes foram entrevistados acerca de como interagem e compartilham conhecimento entre si e também com os fregueses. Já os clientes foram entrevistados acerca da forma como interagem e compartilham conhecimentos com os feirantes e outros clientes. As entrevistas duraram em média 30 minutos.

Os feirantes (donos de barracas fixas) e clientes foram abordados na feira livre e convidados a participarem do referido estudo, bem como esclarecidos acerca dos objetivos e procedimentos que seriam usados. As entrevistas foram feitas e gravadas, mediante a anuência de cada participante. A escolha dos feirantes se baseou em entrevistar pelo menos um de cada segmento de comércio da feira. Quanto aos clientes, os critérios adotados foram a acessibilidade e a saturação.

As entrevistas foram transcritas na íntegra e, em seguida, analisadas conforme a técnica de análise de conteúdo, proposta por Bardin (2011). Inicialmente, as falas dos entrevistados foram analisadas separadamente, levando em consideração o grupo de feirantes e o grupo de clientes. Como algumas falas não vieram na ordem em que as perguntas foram feitas durante a entrevista, houve a condensação destas, seguindo, para efeito de análise, o objetivo de pesquisa previamente definido neste estudo. Além disso, após ler várias vezes as entrevistas de cada grupo (clientes e feirantes), observaram-se semelhanças nas falas dos entrevistados, o que possibilitou aos autores deste artigo, respaldados na literatura investigada, no teor do conteúdo coletado e também nos objetivos previamente definidos, agrupar tanto as falas dos feirantes (F) quanto as falas dos clientes (C).

\section{RESULTADOS}

Dos 25 feirantes, 16 são do sexo masculino e 09, feminino, com faixa etária entre 26 e 75 anos. 0 nível de escolaridade predominante é o ensino médio completo (8); seguidos do ensino fundamental completo (4), ensino fundamental incompleto (4) e ensino superior (4); ensino médio incompleto (3), ensino superior incompleto (1); e pós-graduação incompleta (1). Os tipos de produtos comercializados são variados e vão desde gêneros alimentícios (temperos, queijo, mel e bolos, frutas, legumes, verduras, goma, carne de charque e de sol), até utensílios, redes, roupas, ferragens, sandálias, DVD, flores, mercadinho, bar e lanchonete, artigos de couro e cereais, grãos e estivas. Quanto ao tempo que trabalham na feira, este variou de 04 até 60 anos.

Em relação aos 10 clientes, três são do sexo masculino e sete, feminino, com faixa etária entre 25 e 70 anos. Dois são divorciados e oito são casados. Quanto às profissões, observou-se: professor (03); vendedor (02); comerciante (01); empresária (01); enfermeira (01); engenheiro agrônomo (01); do lar (01). 


\section{Compartilhamento e criação de conhecimentos entre feirantes e fregueses}

No que se refere à maneira como os feirantes compartilham conhecimentos com os fregueses, notou-se que a maioria dos entrevistados informou procurar ter um relacionamento "bom" ou "maravilhoso" com os fregueses. Ou seja, eles buscam ter um "jogo de cintura", fazendo de conta, às vezes, que não veem ou não ouvem certos problemas para superarem os conflitos oriundos da relação com os clientes; esforçamse para transformar relacionamentos tensos e ruins em amigáveis, a fim de que os clientes voltem a comprar em suas barracas, fidelizem-se e tragam rentabilidade. Além disso, procuram "livrar-se" dos clientes que estão atrapalhando o ambiente a fim de evitar mal-estar aos demais, como pode ser observado nas seguintes falas:

[...] você tem que em muitas coisas: ver e fazer que num vê, escutar e fazer que num escuta. Muitas coisas têm que entrar num ouvido e sair no outro [...]coisas boas agente guarda [...]. Essas coisas ruins a gente joga no mato, não fica conosco [...] (F12)

Ah eu tenho que me relacionar muito bem com eles, tratar ele melhor do que o pessoal em casa, porque eles que me mantêm (F8).

Os relacionamentos com os fregueses não são quaisquer relacionamentos, são "aqueles" relacionamentos que inspiram confiança, lealdade, amizade, maximizando assim, a relevância do conhecimento que precisa ser compartilhado. Os feirantes demonstraram ter preocupação para que o ambiente se torne favorável a troca de informações, a relações amistosas, como se depreende das falas a seguir, concorrendo, por conseguinte, ao compartilhamento de informações, como asseveram Nonaka, Toyama e Bonno (2000).

[...] às vezes chega um cliente brabo e sai alegre, né? A gente faz aquela [...], ajeita ele, né? Faz aquela amizade boa, então, se tornamos grandes amigos (F4).

[...] se você trata um cliente mal, ele vai propagar para 10 pessoas no mínimo e se você tratar ele bem, ele vai propagar só pra duas, então você viu a diferença na porcentagem, então é isso (F9).

Todos os entrevistados disseram que não devem tratar o cliente mau, o que para eles significa enganar ou explorar o cliente com mercadorias sem qualidade ou com preços excessivos. Informaram que devem tratar bem o cliente para evitar propaganda negativa e mesmo sendo maltratados pelos fregueses, devem tratá-los bem e, se necessário, ficar calados para evitar embate ou para não se igualar a eles, como demonstram as seguintes respostas:

Enganar o cliente. Dizer que o produto é novo sem ser. Dizer que vai ter uma mercadoria em tal dia e não ter. Ou dizer que vai guardar a mercadoria para o freguês e não guardar (F12).

A mercadoria ruim que a gente tem não coloca para vender, [Ex] no caso da goma mesmo, ela tem muito problema, quando ela vem sem lavar ela fica azeda. Aí o cliente faz a tapioca com ela azeda e não presta. Aí [...] a gente tem que encostar, não pode vacilar, se não perde o cliente (F15).

Apenas um entrevistado disse que o relacionamento com o freguês era tenso e difícil, alegando que a principal dificuldade consiste na desvalorização ou depreciação da mercadoria pelo cliente, apesar da mercadoria ser de boa qualidade, conforme ilustra a fala abaixo:

Já é meio difícil, meio complicado, porque assim, às vezes, a gente tem que atender de uma forma que possa ser bom pra mim e pra ele, mas, às vezes, os clientes são muito exigentes 
e falta paciência pra eles, muita [...]. Por exemplo, fala que a carne não está boa, estando boa, entendeu? E exige, é, fica bem complicado, mas assim, a gente já tem uma experiência, a gente sabe que tem que ter paciência mesmo e tentar levar na boa (F13).

Note que, mesmo sendo difícil a interação com os clientes, os feirantes procuram compreendê-los, silenciar diante das ofensas recebidas, a fim de preservar a relação e evitar danos, como a propaganda negativa. Este resultado é confirmado por Samara e Morsch (2005), ao declararem que a compreensão das necessidades e desejos dos clientes, aliados à busca de estratégias que os tornem continuamente satisfeitos, consiste num diferencial competitivo, que agrega valor ao negócio e também favorece oportunidades de desenvolvimento e expansão organizacional. No que tange ao compartilhamento em si, algumas falas dos clientes revelam a obtenção de conhecimento a partir do conhecimento dos feirantes, a saber:

Eu adoro vir a feira conversar com dona Severina do feijão. Outro dia, ela me deu uma receita de chá ... de umas raízes para inchaço de perna e funcionou" (C2).

Adoro conversar com outros clientes. Outro dia, estava na barraca de $\mathrm{S}[\ldots]$, querendo comprar goma [...], mas sem saber como fazer uma boa tapioca. Aí uma mulher, outra cliente, disse que eu podia levar a goma pois era muito boa. Disse também que eu pegasse uma frigideira colocasse no fogo e só depois de aquecida [...] botasse a massa (C8).

$O$ fato da interação entre feirantes e fregueses ser permeada de sentimentos e valores baseados na confiança, respeito, sinceridade e honestidade, no que diz respeito a informar ao cliente as reais características do produto que comercializam, sem enganá-lo e nem explorá-lo, além de respeitar o freguês como pessoa é também confirmado na literatura de marketing, como sendo estratégias eficazes para atrair, manter e fidelizar clientes no atual mercado competitivo (KARSAKLIAN, 2004; SAMARA et al., 2005).

Registre-se que as emoções, crenças e valores interferem no compartilhamento de conhecimentos (NOVAES, 1980; BOCK; FURTADO; TEIXEIRA, 2008). Portanto, as relações amistosas na feira livre favorecem tal aspecto, como foi evidenciado nas entrevistas.

\section{Compartilhamento e criação de conhecimentos entre os próprios feirantes}

As falas dos entrevistados em relação a forma como compartilham e criam conhecimentos entrei si, dividiram-se em três blocos: a) os que compartilham informações entre si, de maneira "super bem", com respeito e amizade, alegando que são uma família e que devem evitar chatices, intrigas e abusos; b) os que declararam distanciamento para evitar chatices; c) os que declararam existir entre eles deslealdade e desunião. As falas abaixo ilustram:

[...] A gente não pode se negar, a gente tem que tá sempre disposto a ajudar um ao outro, porque isso aqui é uma comunidade, é uma irmandade, tá entendendo? Se um dia eles precisar de mim, se eu puder ajudar, eu ajudo da melhor forma possível e no dia que eu precisar deles, eles também, com certeza, vão me ajudar da melhor forma possível (F7).

Bom, bom, bom, faz 45 anos que eu trabalho aqui na feira, eu não tenho intrigado e não tenho abusado e aconselho a meus vizinhos (F6).

[...] respeitar a todos, dá atenção a todos, que é pra no dia a dia ter um bom relacionamento, né? Não ter aquela coisa de um dia tá de um jeito, outro dia tá de outro, a gente tem que tá da mesma forma todos os dias (F7).

É bom também, é amigável, a gente se comunica, é bem amigável, não há problemas (R13).

[...] ela pra lá e eu pra cá, só no meu canto, não sou de tá junto, conversando, batendo papo não, eu sempre sou assim como ele falou, tanto em casa como no trabalho, meu 
comportamento é esse, faço meu trabalho e falo com as pessoas (F14).

Notou-se através das falas que os feirantes interagem entre si de maneira diferenciada, o que implica em várias atmosferas laborais. Os que interagem de maneira amigável, com respeito e procurando ajudar uns aos outros, estão inseridos numa atmosfera laboral propícia ao compartilhamento e criação de conhecimentos, conforme pode ser confirmado na literatura, mediante os estudos de Nonaka et al. (2000).

O distanciamento e a deslealdade são entendidos aqui como sendo aspectos que interferem negativamente na construção do "Ba" e consequentemente no compartilhamento e criação do conhecimento. O estudo de Morandim (2003) demonstrou que no compartilhamento de conhecimento, podem ocorrer algumas dificuldades ou obstáculos, tais como: linguagem, emoções, crenças, valores etc.

O compartilhamento de conhecimento é passado de geração a geração, de maneira vivencial. A figura paterna destaca-se como elemento transmissor de conhecimento para os filhos e demais pessoas, segundo as falas a seguir:

Aprendi com meu pai. la com ele para o mercado [...] via ele escolher, comprar e pagar a mercadoria. Aí aprendi a comercializar [...] (F20).

Aprendi e conhecer a carne, vendo meu pai cheirar e pegar na carne (F23).

Desde pequena, eu ia para as feiras com o meu pai. Cresci, vendo a forma como meu pai tratava os fregueses, ou seja, sempre de maneira atenciosa e alegre. A feira é uma escola (F18).

Ao buscar saber o que um feirante não pode fazer com outro feirante, observou-se, através das falas deles, que os feirantes não podem ser desleais uns com os outros; nem ultrapassar, derrubar, disputar ou passar por cima e nem discutir uns com os outros. Em vez disso, devem buscar serem leais uns com os outros, ajudar no que for possível, serem unidos. As falas ilustram:

[...] uma concorrência desleal, muita das vezes querendo atrair o cliente para ele, muitas das vezes convidando o cliente a vir pro estabelecimento, já o cliente estando no estabelecimento dele e tratar realmente o seu vizinho, que nós vivemos uma parte da nossa vida aqui e somos como famílias e se não puder e não tivermos cuidado em se relacionar bem, certamente, como vai ser? (F2)

[...] querer ultrapassar o que aquele feirante que está ali do seu lado trabalhando, está ali no dia a dia, eu sei que a gente vê muito isso, sabe? Mas eu tenho tentado né, a cada dia ajudar um aqui, eu aqui com o meu vizinho, graças a Deus, a gente se dá super bem, eu tenho ajudado um e ele tem me ajudado também e é maravilhoso pra nós estarmos reunido assim, trabalhando junto e eu tenho muito respeito pra eles (F1).

Tentar subir em cima dele, derrubar o seu próximo não pode fazer isso, tem que deixaras coisas acontecerem naturalmente (F4).

Acho que discutir um com o outro, porque aqui a gente tá junto todo dia, tá todo mundo fazendo a mesma coisa, precisa trabalhar também e tá discutindo um com o outro e você tá naquela rotina do dia a dia vendo aquela pessoa, isso aí acho que não seria legal não (F8).

Mais uma vez, as falas dos feirantes mostraram que a concorrência desleal, o querer "passar por cima", disputar ou discutir com os outros feirantes são aspectos que interferem negativamente na construção de um ambiente propício ao compartilhamento de conhecimento, o que pode ser confirmado a partir dos estudos de Nonaka et al. (2000).

Apesar do presente trabalho não ter se dirigido ao papel do governo e demais órgãos públicos na feira, notou-se, mediante o "tom" das falas dos feirantes, uma certa crítica, no que se refere à falta de 
estrutura, falta de segurança e de apoio ao comércio da feira, conforme ilustram as falas:

Ter respeito até pelos órgãos públicos que muitas vezes falta na feira central (F9).

Ter respeito na própria estrutura, na segurança, que muitas vezes não temos o apoio do governo (F9).

A feira é um espaço público que requer apoio dos entes governamentais, em termos de melhoria de infraestrutura (SÁ, 2010), sob pena de sua precarização.

\section{CONSIDERAÇÕES FINAIS}

Ao longo deste estudo, procurou-se identificar como os feirantes compartilham conhecimentos entre si e com os fregueses, destacando a criação do conhecimento. Os feirantes entrevistados comercializam produtos diversificados na Feira Central de Campina Grande, tais como: gêneros alimentícios (frutas, queijo, doces, temperos), produtos têxteis e de couros (roupas, redes, sandálias), utensílios domésticos, CDs e flores. A não especificação de um determinado segmento de comércio ocorreu em virtude de se buscar, nesse momento, "mapear" ou conhecer, de maneira exploratória, como ocorre o processo de compartilhamento de conhecimentos.

A feira livre, além de ser um patrimônio cultural da cidade, exercendo relevante papel à comunidade, constitui-se num canal de comercialização diferenciado e também gerador de emprego e renda para o município (CARDOSO et al., 2010).

O dia a dia do trabalho na feira é marcado por diversos paradoxos, que podem ser evidenciados através da maneira como os feirantes se relacionam com os fregueses e com os outros feirantes (SALES et al., 2011; SÁ, 2010).

Um desses paradoxos se refere à forma como os feirantes se relacionam. Os resultados da pesquisa mostraram que a forma como os feirantes compartilham conhecimentos com os fregueses é diferente da maneira como eles compartilham conhecimentos entre si. Os feirantes procuram estabelecer uma relação transparente, de confiança e amizade com os fregueses, marcada pela alegria e bom humor e ao mesmo tempo, usam estas estratégias, o humor, como uma maneira de driblar as tensões e dificuldades dos conflitos advindos da relação com os fregueses, favorecendo assim, o compartilhamento e criação de conhecimentos.

Por outro lado, na relação com os outros feirantes, detectaram-se três diferentes maneiras de interação: alguns feirantes interagem entre si, como se fosse uma família; outros de maneira distante e superficial a fim de evitar conflitos e, outros de maneira hostil. A superficialidade das interações, aliadas aos sentimentos de medo, desconfiança e comportamentos de deslealdade, próprios de um ambiente supercompetitivo, interferem negativamente na constituição do "Ba", no compartilhamento de informações e por conseguinte na criação de conhecimentos inovadores para a organização. Consigne-se também a necessidade de os entes públicos buscarem dar um melhor suporte em infraestrutura, com vistas a propiciar melhores condições aos feirantes.

A presente investigação apresenta como uma das limitações não ter se aprofundado, por meio de uma observação demorada das relações entre os comerciantes e clientes, de modo que se perscrutasse de forma mais contundente a maneira como ocorre o compartilhamento de conhecimento em pauta. Isto 
requereria muito tempo, como uma pesquisa etnográfica. Os achados da pesquisa, todavia, reforçam a necessidade de continuar investigando a maneira como os feirantes compartilham informações com os demais stakeholders: administradores da feira, governo, estado e comunidade.

Diante do exposto, a presente pesquisa revelou um avanço no conhecimento acerca do compartilhamento e criação de conhecimento dos feirantes que atuam em uma feira livre. No entanto, há muito a ser explorado e pesquisado sobre o assunto. Observa-se, então, que o trabalho ainda está em processo de construção. Assim espera-se que esta pesquisa tenha contribuído para gerar e provocar questionamentos que direcionem a exercícios de diálogos e reflexões sobre o assunto estudado. Para próximas pesquisas, como agenda, sugere-se a inclusão do cliente e da administração geral da feira, a fim de que conhecer como eles compartilham e criam conhecimentos.

\section{REFERÊNCIAS}

ARGOTE, L.; INGRAM, P.. Knowledge transfer: a basis for competitive advantage in firms. Organizational Behavior and Human Decision Processes, v.82, n.1, p.150-169, 2000.

BARDIN, L.. Análise de conteúdo. São Paulo: Atlas, 2011.

BENNETT, R.. "Ba" as a determinant of salesforce effectiveness : an empirical assessment of the applicability of the Nonaka-Takeuchi model to the management of the selling function. Marketing Intelligence \& Planning, v.19, n.3, 2001.

BOCK, A. M. B.; FURTADO, O.; TEIXEIRA, M. DE L. T.. Psicologias: uma introdução ao estudo da psicologia. São Paulo: Saraiva, 2008

CARDOSO, C. A. DE A.; MAIA, D. S.. A Feira de Campina Grande: onde se encontra o moderno e o tradicional. In. ENCONTRO NACIONAL DE GEÓGRAFOS, 16. Anais. Porto Alegre: AGB, 2010.

CAVEDON, N.. "Pode chegar, freguês": A cultura organizacional do mercado público de Porto Alegre. In.: ENCONTRO NACIONAL DA ASSOCIAÇÃO NACIONAL DE PÓSGRADUAÇÃO E PESQUISA EM ADMINISTRAÇÃO, 26. Anais. Rio de Janeiro: ANPAD, 2002.

COLLINS, H. M.. The structure of knowledge. Social Research, v.60, n.1, p.95-116, 1993.

CRESWELL, J. W.. Projeto de pesquisa: métodos qualitativo, quantitativo e misto. 3 ed. Porto Alegre: Artmed, 2010.

FAYE, C.; LORTIE, M.; DESMARAIS, L.. Guide to knowledge transfer: designed for researchers in occupational health and safety. Québec: Réseau de recherche en santé et en sécurité du travail du Québec, 2008.

FERREIRA, C. M. A.; WANDERLEY, D. M. A.; FERREIRA, D. J. L. Percepção dos impactos ambientais na Feira Central de Campina Grande. Revista Educação Agrícola Superior, v.26, n.1, p.3-6, 2011.

GIZ DIGITAL. Feira livre: definição história e origem. 2016.
GOMES, A. F.; SILVA, J. S. F.; SANTOS, A. A.; SANTANA, W. G. P.; SANTOS, J. A. G.. Perfil socioeconômico de mulheres feirantes: um estudo no interior baiano. ENCONTRO DE ADMINISTRAÇÃO POLÍTICA, 4. Anais. Vitória da Conquista: UESB, 2013.

GUBBINS, C.; CORRIGAN, S.; GARAVAN, T. N.. Evaluating a tacit knowledge sharing initiative : a case study. Europan Journal of Training and Development, v.36, n.8, p.827-847, 2012.

KARSAKLIAN, E.. Comportamento do consumidor. 2 ed. São Paulo: Atlas, 2004.

MAIOR, A. S.. História Geral. São Paulo: Companhia Editora Nacional, 1978.

MORANDIM, D. R. A. L.. A influência da confiança na transferência do conhecimento. Dissertação (Mestrado em Administração) - Universidade Presbiteriana Mackenzie, São Paulo, 2003.

NONAKA, I.. A dynamic theory of organizational knowledge creation. Organization Science, v.5, n.1, p.14-37, 1994.

NONAKA, I.; KONNO, N.. The Concept of "Ba": Building a Foundation for Knowledge Creation. California Management Review, v.40, n.3, p.40-54, 1998.

NONAKA, I.; VON KROGH, G.. Tacit knowledge and knowledge conversion : controversy and advancement in organizational knowledge creation theory. Organization Science, v.20, n.3, p.635-652, 2009.

NONAKA, I.; TAKEUCHI, H.. The knowledge-creating company: how japanese companies creates the dynamics of innovation. 1995.

NONAKA, I.; TAKEUCHI, H.. Teoria da criação do conhecimento organizacional. In: H. TAKEUCHI; I. NONAKA. Gestão do conhecimento. Porto Alegre: Bookman, 2008. p.54-90.

NONAKA, I.; TOYAMA, R.; KONNO, N.. SECI, Ba and leadership: a unified model of dynamic knowledge creation. Long Range Planning, v.33, p.5-34, 2000. 
NOVAES, M. H.. Psicologia escolar. Petrópolis: Vozes, 1980.

SÁ, M. G.. Feirantes: Quem São? Como Administram seus Negócios? In.: ENCONTRO NACIONAL DA ASSOCIAÇÃO NACIONAL DE PÓS-GRADUAÇÃO E PESQUISA EM ADMINISTRAÇÃO, 17. Anais. Rio de Janeiro: ANPAD, 1993.

SALES, A. P.; REZENDE, L. T.; SETTE, R. S.. Negócio feira livre: um estudo em um município de Minas Gerais. In.: ENCONTRO DE GESTÃO DE PESSOAS E RELAÇÕES DE TRABALHO, 3. Anais. João Pessoa: ANPAD, 2011.
SAMARA, B. S.; MORSCH, M. A.. Comportamento do consumidor: conceitos e casos. São Paulo: Prentice Hall, 2005.

SEKARAN, U.. Research methods for business: a skill building approach. 4 ed. New Jersey: John Wiley \& Sons, 2003.

SZULANSKI, G.. Exploring internal stickiness: impediments to the transfer of best practice within the firm. Strategic Management Journal, v.17, p.27-43, 1996.

TSOUKAS, H.. Do we really understand tacit knowledge? In: EASTERBY-SMITH, M; LYLES, M. A.. Handbook of organizational learning and knowledge management. Boston: Blackwell Publishing, 2007. 